\title{
Whole-body vibration exposure in sport: four relevant cases
}

Marco Tarabini, Bortolino Saggin, Diego Scaccabarozzi

Politecnico di Milano, Dipartimento di Meccanica, via Previati 1/C, 23900 Lecco (Italy)

\begin{abstract}
This study investigates the whole-body vibration exposure in kite surfing, alpine skiing, snowboarding and cycling. The vibration exposure was experimentally evaluated following the ISO 2631 guidelines. Results evidenced that the most critical axis is the vertical one. The weighted vibration levels are always larger than $2.5 \mathrm{~m} / \mathrm{s}^{2}$ and the vibration dose values are larger than $25 \mathrm{~m} / \mathrm{s}^{1.75}$. The exposure limit values of the EU directive are reached after 8 to 37 minutes depending on the sport. The vibration magnitude is influenced by the athletes' speed, by their skill level and sometimes by the equipment. The large vibration values suggest that the practice of sport activities may be a confounding factor in the etiology of vibration-related diseases.
\end{abstract}

\section{Practitioner Summary}

The vibration exposure in some sports is expected to be large, but has never been quantified in the literature. Results of experiments performed in cycling, alpine and water sports outlined vibration levels exceeding the EU standard limit values.

\section{Introduction}

Different studies evidenced that severe and/or prolonged vibration exposure increases the risk of low back pain (LBP) and early spine degeneration, although the correlation between whole-body vibration (WBV) exposure and spine problems varies considerably (Gallais, 
Griffin 2006, Seidel 2005). The conclusion of several literature reviews (Seidel, Heide 1986, Bovenzi, Hulshof 1999, Lings, Leboeuf-Yde 2000) is that the vibration can increase the risk of LBP because of degenerative changes of the vertebrae and disks. The lumbar part of the vertebral column is usually the most affected one; the incidence on the thoracic and cervical parts is of minor importance (Seidel 2005).

Review papers derived almost uniformly that it is impossible to identify an exact exposureeffect relationship from epidemiological studies; the possible reasons for such a lack of correlation are (Seidel 2005):

- the estimation of exposure by questioning the daily working hours and gathering the vibration from databases provides an information whose uncertainty is large;

- workers usually overestimate their working hours;

- the intrinsic variability of WBV measurements is large (Moschioni, Saggin \& Tarabini 2010);

- different anthropometric characteristics and postures greatly vary the vibration transmission between the source and the human body (Tarabini et al. 2013);

- the basic evaluation method using the weighted RMS acceleration may underestimate the risk if the exposure contains high transient or shocks; and

- the supposed stronger effect of WBV in $\mathrm{x}$ and $\mathrm{y}$ axes is reflected in the adoption of the multiplying coefficients $\mathrm{k}=1.4$, although the evidence for this evaluation is missing.

Additionally, there might be other confounding factors not included in the regression models as, for instance, the practice of sport activities: the effect of sports on back pathologies has already been analyzed in the literature with different conclusions. For instance, the practice of cross country ski (which is intuitively characterized by a low vibration levels) increase the risk of low back pain (Bahr et al. 2004), while the practice of alpine ski does not increase the LBP risk (Peacock et al. 2005). The number of studies related to musculoskeletal stress, pain and discomfort in kite surfing is limited (Lundgren, Brorsson \& Osvalder 2012, Lundgren et al. 2011). However, kitesurfers often experience 
high musculoskeletal stress for short times during a session (jumps, tricks and strong winds), and lower, static musculoskeletal stress over a longer time. Cyclists are known to be vulnerable to low back pain (Salai et al. 1999, Manninen, Kallinen 1996, Burnett et al. 2004, Srinivasan, Balasubramanian 2007) but the etiology is not completely understood. Causative factors are thought to be prolonged forward flexion, mechanical creep and generation of high mechanical loads while being in a flexed position; altered motion control and kinematics of the lower lumbar spine were also proven to be associated with the development of LBP in cyclists.

This paper aims to describe the results of tests meant to identify the vibration exposure in four sports in which large vibration levels are expected (alpine skiing, snowboarding, cycling and kite surfing). The proposed method is described in section 2. Experimental results are presented in section 3 and discussed in section 4. The paper conclusions are drawn in section 5 .

\section{Method}

WBV exposure was measured using purposely designed measurement systems (Figure 1) derived from the one used for a tests performed on road vehicles (Moschioni, Saggin \& Tarabini 2010). Vibration was measured by single-axis and triaxial piezoelectric accelerometers with nominal sensitivity of 1 and $10 \mathrm{mV} / \mathrm{m} \mathrm{s}^{-2}$. Data were A/D converted by a NI9234 DAQ board and eventually stored on a Samsung Q1 tablet PC. Acceleration time histories were offline analyzed according to the ISO 2631 procedures. Transducers were located close to the interface between the human body and the vibration source. Since the area of contact between the body and the vibrating surface was generally not accessible, the vibration was measured at particular positions (described in the next section) and the transmissibility between these positions and the ISO 2631 suggested ones was evaluated in laboratory tests. The athletes' speed was measured using a GPS antenna and by bike computers. During kite surfing, the wind speed and the waves' height were measured, while 
the snow condition (for alpine ski and snowboard) and the pavement type (cycling) were subjectively classified. All the experiments were performed in accordance with the current safety legislation and with the Politecnico di Milano ethics guidelines. The correlation between the WBV exposure and some possibly influencing quantities (speed, wave/snow/road conditions, equipment) was investigated with $t$-tests and correlation analysis (Montgomery, Runger 2003).

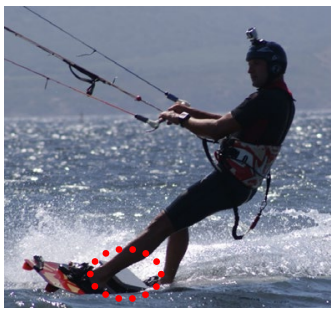

Kite surf

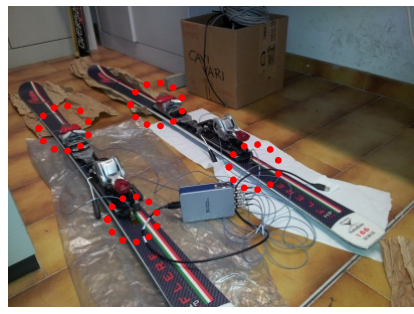

Ski

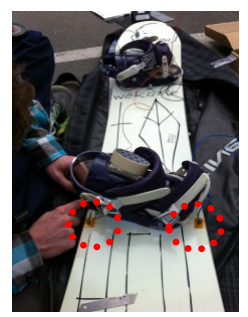

Snowboard

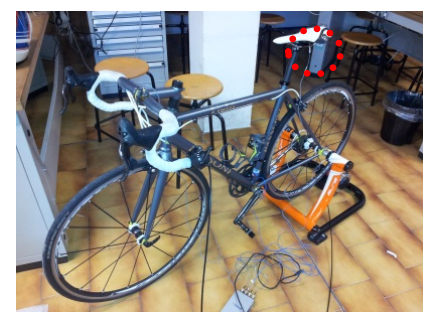

Road bike

Figure 1 Pictures indicating the positioning of accelerometers.

\subsection{Kite surfing}

The main source of vibration in kite surf is the board and according to ISO 2631 accelerometers should be located "at the surface where the feet are most often supported". The accelerometers' position was driven by the necessity of sealing the instrumentation to protect it from the water. The acquisition system was enclosed inside an IP 66 aluminum box (as per DIN 40050), and the box was screwed to the board. A triaxial accelerometer was fixed to the box center, while a single-axis accelerometer was located in different positions in order to detect the amplitude of roll, pitch and yaw motions. The wind speed was measured by a cup accelerometer, while the water conditions were quantified by the vertical acceleration of a $30 \mathrm{~cm}$ diameter buoy located at approximately $30 \mathrm{~m}$ from the shore.

The effect of the box on the board dynamic behavior has been evaluated with two series of laboratory tests, performed on the facility used for previous experiments (Tarabini et al. 2013). Experiments were meant to:

1. evaluate that the vibration transmissibility between the board and the box is unitary; 
2. verify that the vibration transmissibility between the board and the heel with the box is equal to the transmissibility without the box;

Both conditions 1 and 2 were verified (board/box transmissibility within $\pm 5 \%$ range up to $30 \mathrm{~Hz}$, board/heel transmissibility differences comparable to the tests repeatability). Thus, data obtained by the proposed measurement system are a reliable expression of the of subject vibration exposure.

The vibration exposure was evaluated in twelve experimental sessions, performed by a professional kitesurfer, covering a total distance of more than $200 \mathrm{~km}$. Measurements were performed on two locations on the Lake Como (Colico and Valmadrera, Italy) and at Hyeres (France), in different wind/water conditions.

\subsection{Alpine Skiing}

Four single-axis accelerometers were fixed on the skis at the toes and heels of the ski bindings; different tests were required to evaluate the vibration exposure along the $\mathrm{x}, \mathrm{y}$ and $\mathrm{z}$ axes. Also in this case, laboratory tests were performed to identify the vibration transmissibility through the ski bindings and boots (and the transmissibility from the ski to the human body). The meaningfulness of measurements was evaluated comparing the feet to L3 (third lumbar vertebra) transmissibility with and without the skis in a similar posture. Results evidenced that the ski equipment increases the transmissibility from 2 to $8.5 \mathrm{~Hz}$ and that at higher frequencies the transmissibility with the skis is lower than that without the skis. Consequently, the vibration measured at the feet may differ from the vibration exposure with respect of a subject standing over a rigid surface. An estimation of the equivalent vibration exposure is computed in section 3. 


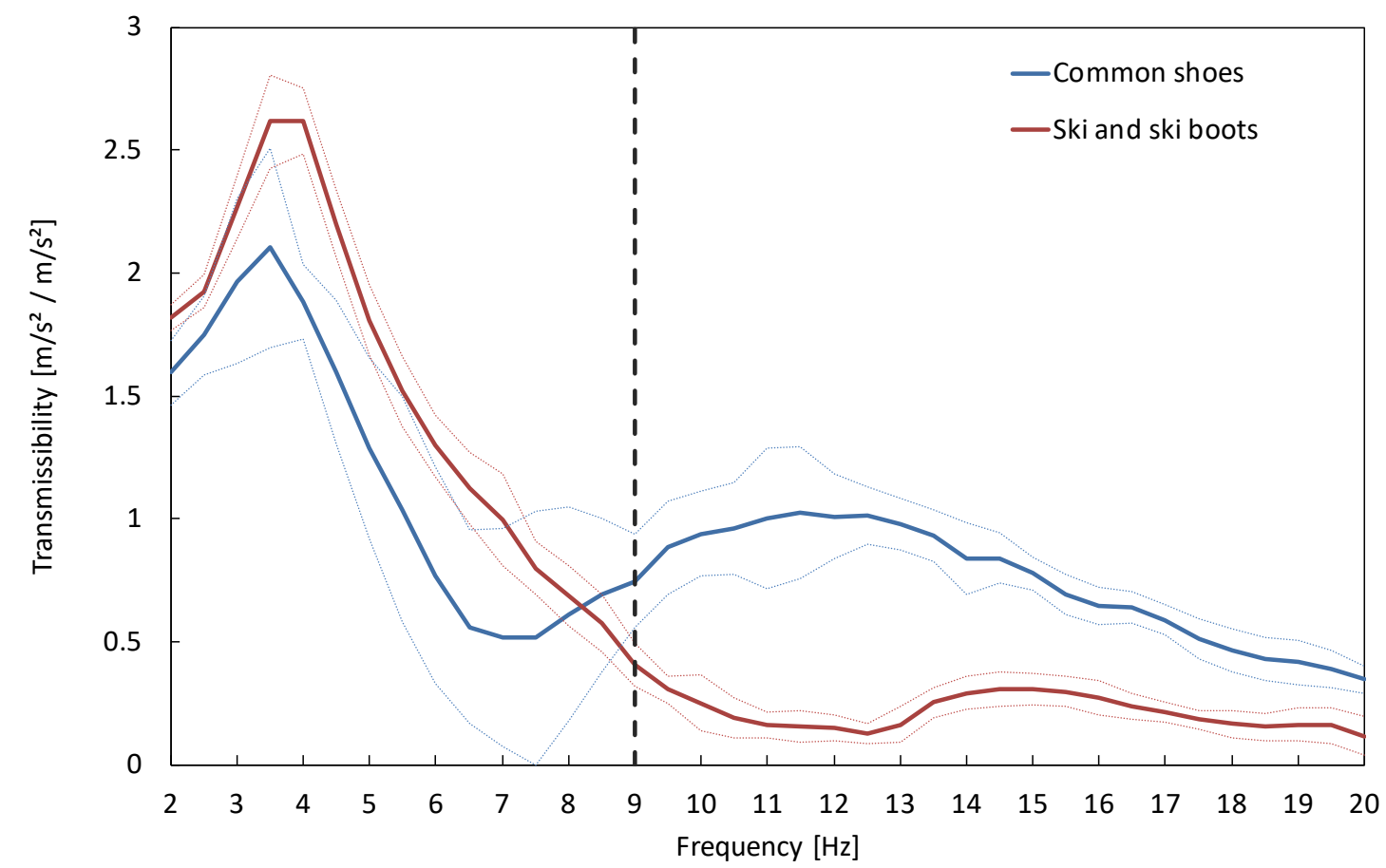

Figure 2: comparison between the feet to L3 transmissibility with and without the skis Uncertainty bands with $2 \sigma$ interval are shown as dot curves.

The vibration exposure of two skiers (a beginner with two years of experience and an advanced skier) has been evaluated both in controlled and non-controlled conditions. In order to investigate the effects of possibly influencing parameters, tests were carried-out on the same ski slope (a red slope in Plateau Rosa, Cervinia, Italy):

- at different speeds: low $(30 \mathrm{~km} / \mathrm{h})$, intermediate $(45 \mathrm{~km} / \mathrm{h})$ and high $(55 \mathrm{~km} / \mathrm{h})$; and

- in different snow conditions (crust snow / slush snow).

Approximately $200 \mathrm{~km}$ of measurements were acquired in uncontrolled conditions to assess the vibration exposure in actual skiing conditions.

\subsection{Snowboarding}

The measurement chain used for snowboard tests was very similar to the one adopted for alpine skiing. Also in this case, four accelerometers were located at the boot toe and heel. Given that the accelerometers position was compatible with the ISO 2631 indications and that the vibration transmissibility of snowboard boots should not differ from that of safety 
shoes, no laboratory tests were performed. Measurements were performed by three skilled athletes (one snowboard instructor and two advanced snowboarders with more than 10 years of experience) during six experimental sessions (five on the ski slopes and one in a training park); in this case, no correlation analyses were performed.

\subsection{Cycling}

The choice of the accelerometer location was driven by two observations: the first is that a consistent part of the cyclist weight is usually supported by the saddle and the second is that the vibration transmissibility through the legs is limited (the knee is always flexed when cycling). Consequently, vibration was measured using a triaxial accelerometer placed on the seat frame, thus neglecting the vibration absorption of the saddle. Similarly to what was done for kite board and skis, the vibration transmissibility from the seat frame to the seat/biker interface was evaluated with laboratory tests on the suspended bikes. Results evidenced that the vibration transmissibility of the road bike and mountain bike seats is unitary (within $\pm 5 \%$ ) up to $40 \mathrm{~Hz}$. The saddle transmissibility of city bikes could not be evaluated in operative conditions and consequently results presented in section 3 may overestimate the actual cyclist exposure.

Tests in controlled conditions were performed with three bikes (road race, mountain bike and city bike) by a single amateur cyclist. The bikes were tested on the same urban path (three tours of a $1 \mathrm{~km}$ ring, totally $3 \mathrm{~km}, 70 \%$ asphalt, $30 \%$ cobblestones). For each bike, 3 tires pressures were tested (6, 7 and 8 bar for the road race, 2, 3 and 4 bar for the mountain bike and city bike). In addition, the road bike was tested in ordinary usage (approximately two hours of measurements).

\subsection{Parameters}

Data were analyzed according to the ISO 2631 method (International Organization for Standardization 1997). The parameters used to quantify the vibration exposure severity were the weighted acceleration levels $\left(a_{\mathrm{wx}}, a_{\mathrm{wy}}, a_{\mathrm{wz}}\right)$, the maximum transient vibration values $\left(\mathrm{MTVV}_{\mathrm{x}}, \mathrm{MTVV}_{\mathrm{y}}, \mathrm{MTVV}_{\mathrm{z}}\right)$ and the vibration dose values $\left(\mathrm{VDV}_{\mathrm{x}}, \mathrm{VDV}_{\mathrm{y}}, \mathrm{VDV}_{\mathrm{z}}\right)$. 
Given that in alpine ski and snowboard the vibration along three axes could not be measured simultaneously, repeatability of the experiments was evaluated repeating the tests in nominally identical conditions. Correlation analysis was used to investigate the dependence of the vibration exposure from the athlete speed and from the environmental conditions.

\section{Results}

The vibration exposure in kite surfing, alpine ski, snowboard and cycling is summarized in Table 1. Data in this section include the results of both the experiments performed in controlled and uncontrolled conditions. The time of sport activity after which the EU directive limit value is reached ranges between 8 minutes (alpine ski) and 80 minutes (mountain bike), evidencing the severity of the exposure.

Table 1: summary of all the tests

\begin{tabular}{|l|c|c|c|c|c|c|c|c|}
\hline & $\begin{array}{c}\text { Measurement time } \\
{[\mathrm{h}]}\end{array}$ & $\begin{array}{c}a_{\mathrm{wx}} \\
{\left[\mathrm{m} / \mathrm{s}^{2}\right]}\end{array}$ & $\begin{array}{c}a_{\mathrm{wy}} \\
{\left[\mathrm{m} / \mathrm{s}^{2}\right]}\end{array}$ & $\begin{array}{c}a_{\mathrm{wz}} \\
{\left[\mathrm{m} / \mathrm{s}^{2}\right]}\end{array}$ & $\begin{array}{c}\mathrm{MTVV}_{\mathrm{z}} \\
{\left[\mathrm{m} / \mathrm{s}^{2}\right]}\end{array}$ & $\begin{array}{c}\mathrm{VDV}_{\mathrm{z}} \\
{\left[\mathrm{m} / \mathrm{s}^{1.75}\right]}\end{array}$ & $\begin{array}{c}\mathrm{T}(\mathrm{EAV}) \\
{[\mathrm{min}]}\end{array}$ & $\begin{array}{c}\mathrm{T}(\mathrm{ELV}) \\
{[\mathrm{min}]}\end{array}$ \\
\hline Kitesurf & 8 & 2.2 & 2.4 & 5.5 & 25 & $65(1 \mathrm{~h})$ & 4 & 20 \\
\hline Alpine ski & 9 & 2.2 & 2.9 & 8.9 & 100 & $95(2 \mathrm{~h})$ & 1.5 & 8 \\
\hline Snowboard & 3 & - & - & 6.1 & 250 & $210(2 \mathrm{~h})$ & 3 & 17 \\
\hline Road Bike & 4 & 1 & 0.8 & 4.1 & 14 & $50(2 \mathrm{~h})$ & 7 & 40 \\
\hline Mountain Bike & 1 & 0.7 & 0.8 & 2.8 & 10 & $25(2 \mathrm{~h})$ & 15 & 80 \\
\hline City bike & 1 & 0.5 & 0.4 & 3.0 & 9 & $26(2 \mathrm{~h})$ & 13 & 70 \\
\hline
\end{tabular}

\subsection{Kite surfing}

The weighted acceleration level, the wind speed, the average sailing speed and the vertical buoy acceleration were computed on data measured between two tacks. Results evidenced that that the vibration exposure (measured at the midpoint between the feet) strongly depends on the sailing speed, as clearly evidenced in the scatterplots of Figure 3. 

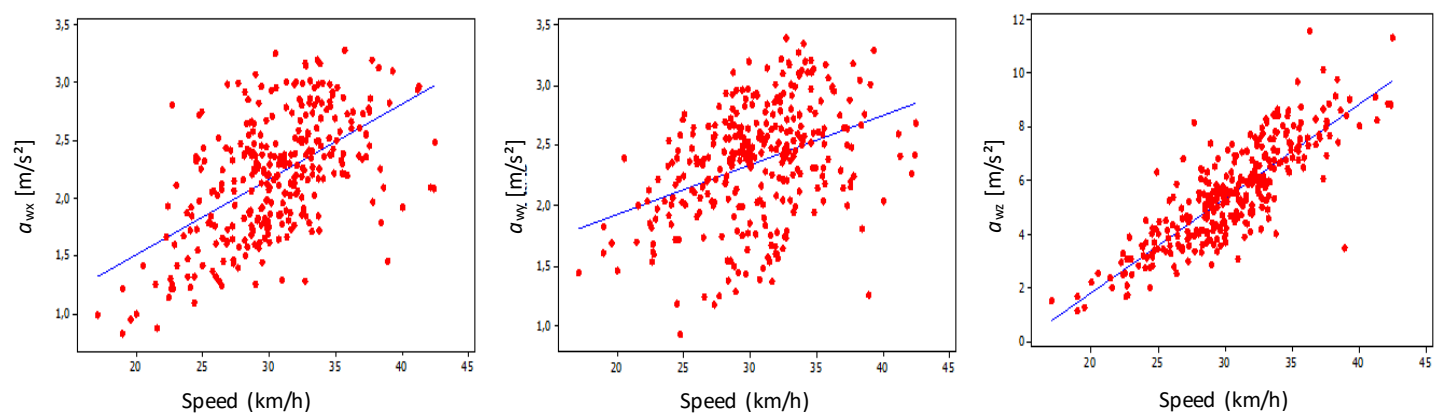

Figure 3 Correlation between the kite surfer speed and the weighted vibration level measured along the three ISO 2631 axes ( $\mathrm{x}, \mathrm{y}$ and $\mathrm{z}$ from left to right)

The effects of the vertical buoy acceleration (summarizing the water conditions) and of the wind were minor: the correlation coefficient between the buoy acceleration and the weighted acceleration ranged between $1 \%(\mathrm{z}$ axis) and $10 \%$ ( $\mathrm{x}$ axis), while the correlation coefficient between the wind speed and the vibration ranged between $1 \%$ (x axis) and $9 \%$ ( $\mathrm{z}$ axis). The limited effect of these two parameters is discussed in section 4 .

Since the board motion is not a pure translation, the exposures of the bow and stern feet are different. Roll, pitch and yaw motions were estimated (under the hypothesis of rigid board) using data collected by the single-axis accelerometer placed in different box positions. The hypothesis of rigid board was verified both in the preliminary shaker tests and confirmed by the FRF between two accelerometers oriented in the same direction. The "worst $a_{\mathrm{w}}$ " in different board positions for left and right motion is shown in Figure 4 (the greyscale shows the vibration level). 


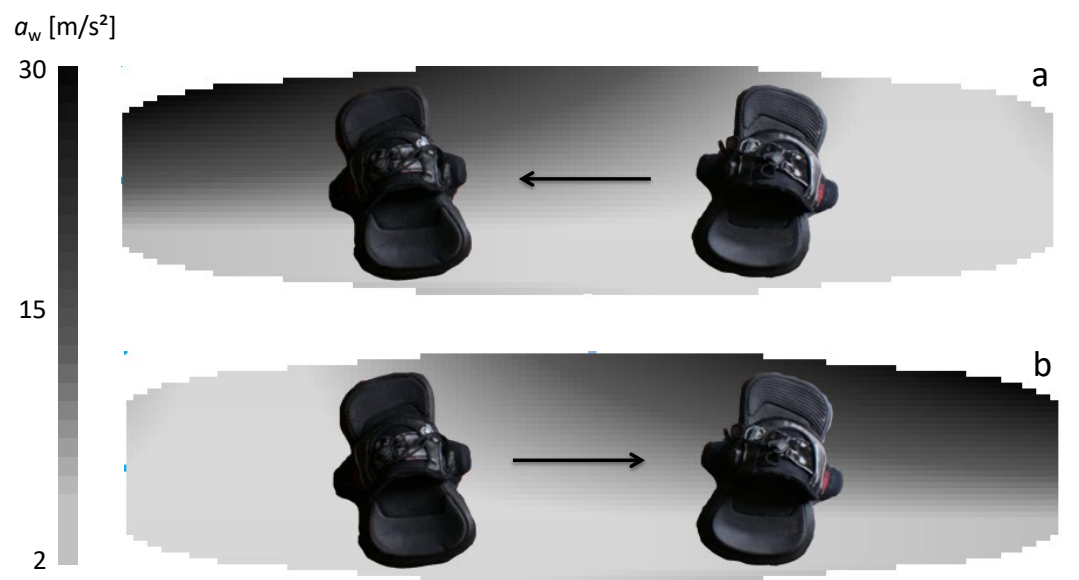

Figure 4: worst $a_{\mathrm{w}}$ distribution on the kite surf board estimated from the average roll, pitch and yaw when the kite surfer is moving from right to left (a) and from left to right (b).

\subsection{Alpine ski}

The effect of the skis to L3 transmissibility was evaluated by estimating the weighted acceleration level at L3 with and without the skis (i.e. by multiplying the average $a_{\mathrm{wz}}$ spectrum measured during the tests by the transmissibilities in Figure 2). Results evidenced that the difference is smaller than $15 \%$, thus confirming the validity of data presented in this paper.

Vibration along the vertical axis is by far the most critical one, and the skis rotations are negligible. $t$-tests results evidenced that assuming an $\alpha$-type risk of $5 \%, a_{\mathrm{z}}$ measured at the toes of the ski bindings is equal to that measured at the heels, and that the vibration measured on the left and right skis are comparable. The effect of snow type was also negligible. As shown in Figure 5, $a_{\mathrm{z}}$ depends both on the athlete skill and on the downhill speed. In particular, the vibration of the skis of the skilled athlete increases with the speed (Figure $5 \mathrm{a}$ ), while the vibration of the beginner is larger when the speed is intermediate (and is larger than the vibration of the advanced skier). 

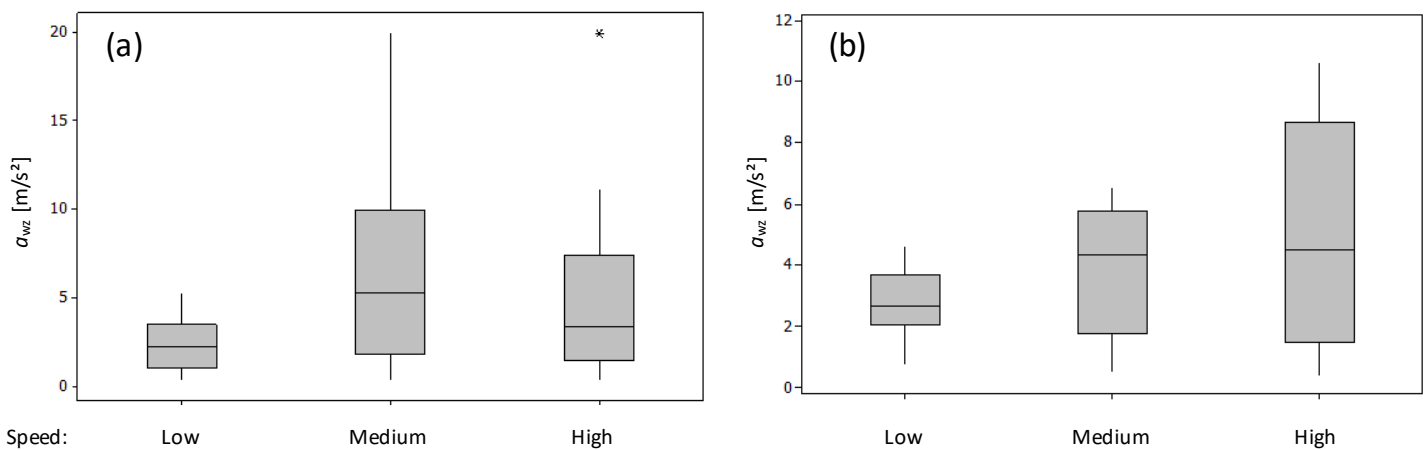

Figure 5: Effect of speed ( $\mathrm{x}$ axis) and the skill (a beginner, $\mathrm{b}$ intermediate) on the skier vertical vibration exposure.

\subsection{Cycling}

The most critical axis is the vertical one and the vibration increases if the road surface is less regular. The effect of speed was more complex: $t$-tests results evidenced that, with $\alpha$ type risk of $5 \%, a_{\mathrm{v}}$ is independent on the speed if the street paving is smooth (new and partially degraded asphalt), while it is speed-dependent if the surface is not uniform (cobblestones). The influence of the tires pressure and bike type is meaningful only if the road surface is irregular. The effect of road type, tires pressure and bike type is shown in Figure 6.
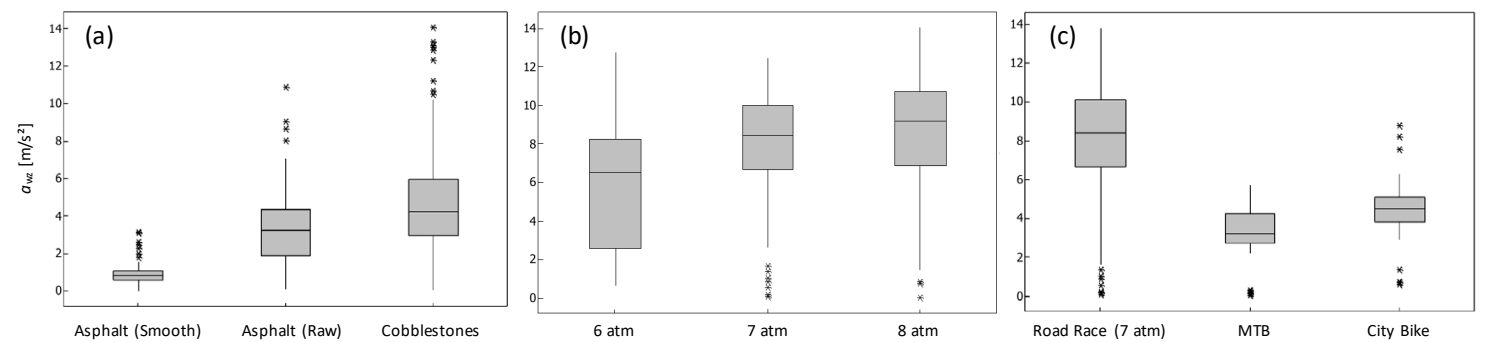

Figure 6 Effect of the street paving (a), of the road race tires pressure (b) and of the bike type (c) on the cyclist vibration exposure.

\section{Discussion}

According to the current ISO standards and EU regulations, the health-related risks of subjects exposed to whole-body vibration can be quantified by the frequency-weighted acceleration or by the vibration dose value. Both quantities assess the risk starting from the 
vibration magnitude and from the duration of exposure. Independently on the adopted criterion, the vibration exposure in the cycling, snowboarding, alpine skiing and kite surfing exceeds the EU directive limits (limit values are always reached after less than 1 hour of activity).

This seems to indicate that the risk of back disorders in athletes practicing these four sports should be large ${ }^{1}$. Existing literature studies evidenced that LBP risk among alpine skiers is not larger than that of the control population (Peacock et al. 2005) while LBP is common among cyclists and kite surfers (Asplund, Webb \& Barkdull 2005, Lundgren et al. 2011), where the vibration exposure is comparatively lower. Considering that cycling is the only sport (among the ones investigated in our study) performed in seated position, the differences due to the posture and to the transmission from the feet or from the seat might play a major role on the etiology of musculoskeletal disorders.

The postures of kite surfers, alpine skiers, and snowboarders significantly differ from the standing one, both because of the knees (that are bent to absorb the vibration) and of the trunk (that is leaning forward in alpine ski and snowboard). Given that the apparent mass of subjects assuming these postures differs from that of people standing in upright position (Tarabini et al. 2013, Subashi, Matsumoto \& Griffin 2006), the power absorption of different body segments during the sport activity may be different from that of people in actual working conditions. From this point of view, the posture importance on the etiology of back disorders seems confirmed.

\subsection{Kite surfing}

Results evidenced that the vibration exposure is mostly affected by the sailing speed; the effect of the wind speed and on the water conditions was more limited. The trivial effect of

${ }^{1}$ Given that the MTVV/ $a_{\mathrm{w}}$ ratio evidenced the presence of severe shocks, the basic ISO 2631 criterion may even underestimate the exposure severity. 
the water conditions has different reasons: tests were performed far from the buoy and, especially on the lake, local phenomena due to boats, ferries, or wind gradients might act as confounders. In addition, the wave conditions during the different experimental sessions were comparable (wave height between 0.2 and $1 \mathrm{~m}$ ).

The effect of the wind speed on the vibration exposure is minor, reasonably because the kite size is chosen depending on the wind speed (smaller kites are chosen with stronger wind). The board roll, pitch and yaw cause a different exposure of the kite surfer feet; the particular athlete posture (shown in Figure 1) implies that the weight is mostly supported by the stern leg, which is flexed and characterized by a lower vibration. Conversely, the bow leg is straight and is not supporting the athlete weight, but the board vibration is averagely larger. The kite propulsion is transmitted to the body using a harness: waist harnesses are the most popular among advanced kite surfers and seat/vest harnesses give beginners more protection from impacts. The presence of a static load (partially acting as a constraint) in the low back region and the difficulty in quantifying the amount of vibration transmitted to the kiter body through the legs cast the doubt about the validity of the ISO 2631 metrics for the evaluation of the vibration exposure severity. However, the high musculoskeletal stress of kitesurfers reported in the literature (Lundgren et al. 2011) may be partially endorsable to the relevant vibration exposure.

\subsection{Alpine skis and snowboard}

Results outlined that the vibration exposure in alpine ski mostly depend on the downhill speed and on the skill level. The vibration measured at the bindings toe and heel was comparable for both in alpine ski and snowboarding, thus evidencing that the roll, pitch and yaw in these sports are negligible.

The exposure difference between a beginner and a skilled alpine skier was only noticed on the basis of results of two subjects; although it is not reasonable to generalize these results, at the same speed, the beginners exposure should be larger than that of skilled skiers. Advanced skiers turns using the sidecut of the skis: the ski sliding is limited, thus minimizing 
the friction and the turning effort. Beginners usually turn using the snowplough technique, in which the skis tips are very close and the tails pushed wide apart: such a posture entails a large turning effort.

The vibration exposure in alpine skiing and snowboarding is relevant, but the specific posture assumed by the athletes reduces the vibration transmitted to the trunk. The low vibration transmissibility through the flexed legs can be one of the reasons for which back pathologies in professional alpine skiers is not different from that of non-skiers (Peacock et al. 2005). The skier posture (flexed knees and trunk leaning forward) is constrained by the ski boots that are characterized by net ankle flexion of approximately $10^{\circ}$; this may suggest that in presence of relevant ground vibration workers should wear safety shoes forcing a flexed knees posture, to reduce the amount of vibration transmitted to the trunk. Although our study is not focused on the therapeutic effect of vibration, our finding is consistent with what is evidenced in the literature, i.e. that WBV has therapeutic effect on the nonspecific LBP, sarcopenia and osteoporosis (Pozo-Cruz et al. 2011, Cardinale, Pope 2003, Cardinale, Wakeling 2005). Since the posture of skiers is similar to the one that people assume on the vibrating platforms, the positive effect of short term vibration in upright position with flexed knees for nonspecific LBP seems confirmed.

\subsection{Cycling}

The cyclists' vibration exposure depends on the bike mechanical characteristics, on the tires pressure, on the road pavement and on the speed. The vibration reaches the cyclist trunk through the seat, through the feet and through the arms of the cyclist; the relative importance of these vibration patterns depends on the cyclist posture, which depends on the bike frame characteristics (Burke, Pruitt 2003). The cyclist trunk is almost upright for city bikes and almost horizontal for time trial, triathlon and track bikes; mechanical stresses on the lumbar discs are therefore expected to depend on the bike type. The dependence of the vibration exposure from a large number of factors reported in our study may be one of the causes for which the etiology of back pain in cyclists is still unclear (Burnett et al. 2004). 


\section{Conclusion}

Results presented in this paper outlined a large vibration exposure of kite surfers, alpine skiers, snowboarders and cyclists. WBV exposure in these sports is not negligible in comparison to the vibration at the workplace and, consequently, the practice of these sports could be included in questionnaires as a confounding factor. The correlation of vibration values and the results of epidemiological studies on the prevalence of LBP in alpine skiers (Peacock et al. 2005) and cyclists (Salai et al. 1999, Burnett et al. 2004) indicate the totally different effect of vibration in sitting and standing posture and, in general, the paramount effect of posture in back disorders etiology. Under this perspective, a differentiation of the ISO 2631 weighting curves for sitting and standing postures would be desirable.

\section{References}

Asplund, C., Webb, C. and Barkdull, T., 2005. Neck and back pain in bicycling. Current Sports Medicine Reports, 4 (5), 271-274.

Bahr, R., Andersen, S.O., Løken, S., Fossan, B., Hansen, T. and Holme, I., 2004. Low back pain among endurance athletes with and without specific back loading-a cross-sectional survey of cross-country skiers, rowers, orienteerers, and nonathletic controls. Spine, 29 (4), 449.

Bovenzi, M. and Hulshof, C.T.J., 1999. An updated review of epidemiologic studies on the relationship between exposure to whole-body vibration and low back pain (1986-1997). International Archives of Occupational and Environmental Health, 72 (6), 351-365.

Burke, E.R. and Pruitt, A., 2003. Body positioning for cycling. High Tech Cycling.Champaign, Il.: Humans Kinetics, 69-92.

Burnett, A.F., Cornelius, M.W., Dankaerts, W. and O'Sullivan, P.B., 2004. Spinal kinematics and trunk muscle activity in cyclists: a comparison between healthy controls and non- 
specific chronic low back pain subjects-a pilot investigation. Manual therapy, 9 (4), 211219.

Gallais, L. and Griffin, M.J., 2006. Low back pain in car drivers: A review of studies published 1975 to 2005. Journal of Sound and Vibration, 298 (3), 499-513.

International Organization for Standardization, 1997. ISO 2631: Mechanical Vibration: Evaluation of human exposure to whole-body vibration.

Lings, S. and Leboeuf-Yde, C., 2000. Whole-body vibration and low back pain: A systematic, critical review of the epidemiological literature 1992-1999. International archives of occupational and environmental health, 73 (5), 290-297.

Lundgren, L., Brorsson, S., Hilliges, M. and Osvalder, A., 2011. Sport performance and perceived musculoskeletal stress, pain and discomfort in kitesurfing. International Journal of Performance Analysis in Sport, 11 (1), 142-158.

Lundgren, L., Brorsson, S. and Osvalder, A., 2012. Comfort aspects important for the performance and safety of kitesurfing. Work: A Journal of Prevention, Assessment and Rehabilitation, 41, 1221-1225.

Manninen, J. and Kallinen, M., 1996. Low back pain and other overuse injuries in a group of Japanese triathletes. British journal of sports medicine, 30 (2), 134-139.

Montgomery, D.C. and Runger, G.C., 2003. Applied Statistics and Probability for Engineers: John Wiley \& Sons, Inc.

Moschioni, G., Saggin, B. and Tarabini, M., 2010. Long Term WBV Measurements on Vehicles Travelling on Urban Paths. Industrial Health, 48 (5), 606-614.

Peacock, N., Walker, J.A., Fogg, R. and Dudley, K., 2005. Prevalence of low back pain in alpine ski instructors. The Journal of orthopaedic and sports physical therapy, 35 (2), 106-110. 
Salai, M., Brosh, T., Blankstein, A., Oran, A. and Chechik, A., 1999. Effect of changing the saddle angle on the incidence of low back pain in recreational bicyclists. British journal of sports medicine, 33 (6), 398-400.

Seidel, H., 2005. On the relationship between whole-body vibration exposure and spinal health risk. Industrial health, 43 (3), 361-377.

Seidel, H. and Heide, R., 1986. Long-term effects of whole-body vibration: a critical survey of the literature. International archives of occupational and environmental health, 58 (1), 126.

Srinivasan, J. and Balasubramanian, V., 2007. Low back pain and muscle fatigue due to road cycling-An sEMG study. Journal of Bodywork and Movement Therapies, 11 (3), 260-266.

Subashi, G., Matsumoto, Y. and Griffin, M., 2006. Apparent mass and cross-axis apparent mass of standing subjects during exposure to vertical whole-body vibration. Journal of Sound and Vibration, 293 (1), 78-95.

Tarabini, M., Saggin, B., Scaccabarozzi, D., Gaviraghi, D. and Moschioni, G., 2013. Apparent mass distribution at the feet of standing subjects exposed to whole-body vibration. Ergonomics, 1-14.

Asplund, C., Webb, C. and Barkdull, T., 2005. Neck and back pain in bicycling. Current Sports Medicine Reports, 4 (5), 271-274.

Bahr, R., Andersen, S.O., Løken, S., Fossan, B., Hansen, T. and Holme, I., 2004. Low back pain among endurance athletes with and without specific back loading-a cross-sectional survey of cross-country skiers, rowers, orienteerers, and nonathletic controls. Spine, 29 (4), 449. 
Bovenzi, M. and Hulshof, C.T.J., 1999. An updated review of epidemiologic studies on the relationship between exposure to whole-body vibration and low back pain (1986-1997). International Archives of Occupational and Environmental Health, 72 (6), 351-365.

Burke, E.R. and Pruitt, A., 2003. Body positioning for cycling. High Tech Cycling.Champaign, Il.: Humans Kinetics, 69-92.

Burnett, A.F., Cornelius, M.W., Dankaerts, W. and O'Sullivan, P.B., 2004. Spinal kinematics and trunk muscle activity in cyclists: a comparison between healthy controls and nonspecific chronic low back pain subjects-a pilot investigation. Manual therapy, 9 (4), 211219.

Cardinale, M. and Pope, M., 2003. The effects of whole body vibration on humans: dangerous or advantageous?. Acta Physiologica Hungarica, 90 (3), 195-206.

Cardinale, M. and Wakeling, J., 2005. Whole body vibration exercise: are vibrations good for you?. British journal of sports medicine, 39 (9), 585-9; discussion 589.

Gallais, L. and Griffin, M.J., 2006. Low back pain in car drivers: A review of studies published 1975 to 2005. Journal of Sound and Vibration, 298 (3), 499-513.

International Organization for Standardization, 1997. ISO 2631: Mechanical Vibration: Evaluation of human exposure to whole-body vibration.

Lings, S. and Leboeuf-Yde, C., 2000. Whole-body vibration and low back pain: A systematic, critical review of the epidemiological literature 1992-1999. International archives of occupational and environmental health, 73 (5), 290-297.

Lundgren, L., Brorsson, S., Hilliges, M. and Osvalder, A., 2011. Sport performance and perceived musculoskeletal stress, pain and discomfort in kitesurfing. International Journal of Performance Analysis in Sport, 11 (1), 142-158. 
Lundgren, L., Brorsson, S. and Osvalder, A., 2012. Comfort aspects important for the performance and safety of kitesurfing. Work: A Journal of Prevention, Assessment and Rehabilitation, 41, 1221-1225.

Manninen, J. and Kallinen, M., 1996. Low back pain and other overuse injuries in a group of Japanese triathletes. British journal of sports medicine, 30 (2), 134-139.

Montgomery, D.C. and Runger, G.C., 2003. Applied Statistics and Probability for Engineers: John Wiley \& Sons, Inc.

Moschioni, G., Saggin, B. and Tarabini, M., 2010. Long Term WBV Measurements on Vehicles Travelling on Urban Paths. Industrial Health, 48 (5), 606-614.

Peacock, N., Walker, J.A., Fogg, R. and Dudley, K., 2005. Prevalence of low back pain in alpine ski instructors. The Journal of orthopaedic and sports physical therapy, 35 (2), 106-110.

Pozo-Cruz, B.D., Hernandez Mocholi, M.A., Adsuar, J.C., Parraca, J.A., Muro, I. and Gusi, N., 2011. Effects of whole body vibration therapy on main outcome measures for chronic nonspecific low back pain: a single-blind randomized controlled trial. Journal of Rehabilitation Medicine, 43 (8), 689-694.

Salai, M., Brosh, T., Blankstein, A., Oran, A. and Chechik, A., 1999. Effect of changing the saddle angle on the incidence of low back pain in recreational bicyclists. British journal of sports medicine, 33 (6), 398-400.

Seidel, H., 2005. On the relationship between whole-body vibration exposure and spinal health risk Industrial health, 43 (3), 361-377.

Seidel, H. and Heide, R., 1986. Long-term effects of whole-body vibration: a critical survey of the literature. International archives of occupational and environmental health, 58 (1), 126. 
Srinivasan, J. and Balasubramanian, V., 2007. Low back pain and muscle fatigue due to road cycling-An sEMG study. Journal of Bodywork and Movement Therapies, 11 (3), 260-266.

Subashi, G., Matsumoto, Y. and Griffin, M., 2006. Apparent mass and cross-axis apparent mass of standing subjects during exposure to vertical whole-body vibration. Journal of Sound and Vibration, 293 (1), 78-95.

Tarabini, M., Saggin, B., Scaccabarozzi, D., Gaviraghi, D. and Moschioni, G., 2013. Apparent mass distribution at the feet of standing subjects exposed to whole-body vibration. Ergonomics, 1-14. 